\title{
RETRACTED ARTICLE: Starting Solutions for MHD Flow of an Oldroyd-B Fluid Through Porous Medium in Cylindrical Domains
}

\author{
M. Khan · Madiha Ajmal • C. Fetecau
}

Received: 26 July 2012 / Accepted: 21 October 2012 / Published online: 7 November 2012

(C) Springer Science+Business Media Dordrecht 2013

This paper has been withdrawn at the request of the authors since it contains a number of serious mathematical errors and flaws. The Publisher apologizes for any inconvenience this may cause.

\footnotetext{
M. Khan $(\varangle) \cdot$ M. Ajmal

Department of Mathematics, Quaid-i-Azam University, 44000 Islamabad, Pakistan

e-mail: mkhan_21@yahoo.com; mkhan@qau.edu.pk

C. Fetecau

Department of Mathematics, Technical University of Iasi, 700050 Iasi, Romania

C. Fetecau

Academy of Romanian Scientists, 050094 Bucharest, Romania
} 